\title{
Development of constant-power driving control for light-emitting-diode (LED) luminaire
}

\author{
Bin-Juine Huang*, Chun-Wei Chen, Chin-Dian Ong, Bo-Han Du, Po-Chien Hsu \\ New Energy Center, Department of Mechanical Engineering, National Taiwan University, Taipei 106, Taiwan
}

\section{H I G H L I G H T S}

- A constant-power driving technique is proposed for LED luminaire.

- A linear system dynamics model of LED luminaire is used in the control system design.

- The test shows that the feedback system accurately controls the input power.

- The LED illumination varies slightly $(-1.7 \%)$ for constant-power driving.

\section{A R T I C L E I N F O}

\section{Article history:}

Received 25 October 2011

Accepted 26 July 2012

Available online 4 August 2012

\section{Keywords:}

LED lighting

LED driving

Constant-power driving LED

LED control

LED lighting control

\begin{abstract}
A B S T R A C T
The illumination of an LED may be affected by operating temperature even under constant-current condition. A constant-power driving technique is proposed in the present study for LED luminaire. A linear system dynamics model of LED luminaire is first derived and used in the design of the feedback control system. The PI controller was designed and tuned taking into account the control accuracy and robust properties with respect to plant uncertainty and variation of operating conditions. The control system was implemented on a microprocessor and used to control a 150W LED luminaire. The test result shows that the feedback system accurately controls the input power of LED luminaire to within 1.3 per cent error. As the ambient temperature changes from 0 to $40{ }^{\circ} \mathrm{C}$, the LED illumination varies slightly $(-1.7 \%)$ for constant-power driving, as compared to that of constant-current driving $(-12 \%)$ and constant-voltage driving $(+50 \%)$. The constant-power driving has revealed advantage in stabilizing the illumination of LED under large temperature variation.
\end{abstract}

(c) 2012 Elsevier Ltd. All rights reserved.

\section{Introduction}

High-power LED (light-emitting diode) lighting is considered to be the next-generation lighting technology with high efficiency, long life, and environmentally friendly [1-3]. The application is getting popular in street and indoor lighting after the heat dissipation problem has been solved [4-6] and the lighting efficiency of LED is improved rapidly [7].

The I-V curve of an LED lamp is sensitive in voltage, as shown in Fig. 1. A slight variation of input voltage may cause abrupt change of current which may damage the LED. The constant-voltage driver was thus not recommended for LED driving. Instead, the constantcurrent driving is usually used in commercial products, for example the product of Zetex (2008) [8].

The electrical performance of LED behaves like a kind of negative-temperature resistance. The electrical resistance of LED

\footnotetext{
* Corresponding author. Fax: +886 223640549.

E-mail address: bjhuang@seed.net.tw (B.-J. Huang).
}

decreases with increasing temperature. The driving voltage as well as the input power for a constant-current driven LED may change due to variation of LED junction temperature. An illumination test of a 150W LED luminaire was carried out in the present study and we found that the constant-current driven LED causes an illumination decrease about $12 \%$, and about $50 \%$ increase for constantvoltage driving, for a temperature rise of $40{ }^{\circ} \mathrm{C}$ (Fig. 2).

The test result of Fig. 2(b) has shown that the amount of light emission of an LED is affected by operating temperature even under constant-current condition. This is probably caused by the effect of electron noise inside the diode which results in the decrease of illumination at higher temperature.

In the present study, we intend to develop a constant-power driving technique to provide a constant-power input to the LED. The constant-power driver will balance the current supply as well as the light emission at variable operating temperatures. That is, the light emission can be balanced if the current is increased at higher operating temperature.

The control system design of a constant-power driver of LED is quite complicated since the LED is a diode performing like 


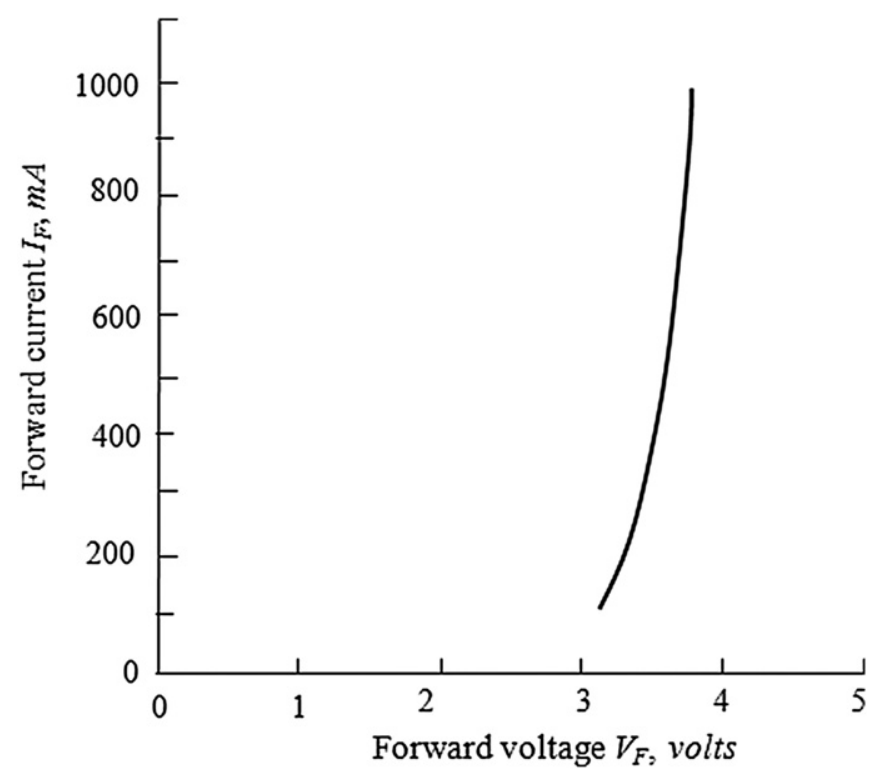

Fig. 1. $I-V$ curve of an LED.

a negative-temperature resistor which results in a nonlinear behavior in feedback control system. A linear feedback control system to provide a constant-power input to the LED luminaire will be developed in the present study. The linear system dynamics model of the LED luminaire is first derived and used in the design of the feedback control system.

\section{System dynamics model of LED luminaire}

\subsection{Derivation of system dynamics model of LED luminaire}

The system dynamics model of LED luminaire developed by Huang et al. [9] is adopted in the present study. The LED lighting luminaire as shown in Fig. 3 [6] consists of three major components: LED lighting module, heat conducting block, and heat sink. The lighting module includes the light sources (i.e. LED lamps) and secondary optics component. LED lamps are attached to a metallic board for electrical connection. The secondary optics component is added on LED lamps to yield the desired illumination distribution. The heat conducting block acts as a thermal connector to the heat sink which is used to dissipate the heat to ambient. The heat sink was designed using loop heat pipe (LHP) attached on the fixture housing.

For a high-power luminaire, the heat conducting block and the heat sink are usually heavy (2-10 kg) compared to the LED lighting module. Hence, the thermal response of the whole luminaire is dominated by the heat conducting body and the heat sink.

Since LED lamp is made from semiconductor, its electrical phenomena is similar to a resistor but with a nonlinear voltage-current relation as shown in Fig. 1. The system dynamics of an LED luminaire thus can be treated as a multiple-input-multipleoutput (MIMO) system with two inputs (voltage $V$ and ambient temperature $T_{\mathrm{a}}$ ) and two outputs (forward current $I$ and body temperature $T_{\mathrm{b}}$ ) [9]. Since the system dynamics model is nonlinear, the following linear-perturbation model in Laplace transform was derived [9]:

$\left[\begin{array}{c}\tilde{T}_{\mathrm{b}}(s) \\ \tilde{I}(s)\end{array}\right]=\left[\begin{array}{cc}G_{\mathrm{vb}}(s) & G_{\mathrm{ab}}(s) \\ G_{\mathrm{vi}}(s) & G_{\mathrm{ai}}(s)\end{array}\right]\left[\begin{array}{c}\tilde{V}(s) \\ \tilde{T}_{\mathrm{a}}(s)\end{array}\right]$

where the perturbed variables in time domain from the equilibrium state are defined as follows:

$\tilde{V}(t)=V(t)-\bar{V}$

$\tilde{T}_{\mathrm{a}}(t)=T_{\mathrm{a}}(t)-\bar{T}_{\mathrm{a}}$

$\tilde{T}_{\mathrm{b}}(t)=T_{\mathrm{b}}(t)-\bar{T}_{\mathrm{b}}$

$\tilde{I}(t)=I(t)-\bar{I}$

Eq. (1) indicates that both $T_{\mathrm{b}}$ and $I$ are affected by ambient temperature $T_{\mathrm{a}}$ and applied voltage $V$ which can be written as, in transfer-function form:

$\tilde{T}_{\mathrm{b}}(s)=G_{\mathrm{vb}}(s) \times \tilde{V}(s)+G_{\mathrm{ab}}(s) \times \tilde{T}_{\mathrm{a}}(s)$

$\tilde{I}(s)=G_{\mathrm{vi}}(s) \times \tilde{V}(s)+G_{\mathrm{ai}}(s) \times \tilde{T}_{\mathrm{a}}(s)$

Fig. 4 shows the MIMO system block diagram.

The LED lighting luminaire is a $2 \times 2$ system with two inputs ( $V$ and $T_{\mathrm{a}}$ ) and two outputs $\left(I\right.$ and $\left.T_{\mathrm{b}}\right)$. The dynamic model consists of four components, $G_{\mathrm{vb}}(s), G_{\mathrm{vi}}(s), G_{\mathrm{ab}}(s)$, and $G_{\mathrm{ai}}(s)$.

The model components $G_{\mathrm{vb}}(s)$ and $G_{\mathrm{ab}}(s)$ are related to the response of heat conducting block temperature $T_{\mathrm{b}}$ due to the change of the applied voltage $V$ and the ambient temperature $\left(T_{\mathrm{a}}\right)$.

Since the purpose of the present study is to develop a constantpower control system for a high-power LED luminaire, the simplified dynamics model as shown in Fig. 5 can be used which consists of the current model $G_{\mathrm{vi}}(s)$ and the temperature disturbance model $G_{\mathrm{ai}}(s)[9]$.

For constant-power driving control, the system dynamics model has to be modified to include input power of the LED luminaire as one of the outputs. The instantaneous power input to the LED luminaire $P(t)$ can be expressed as Eq. (8):
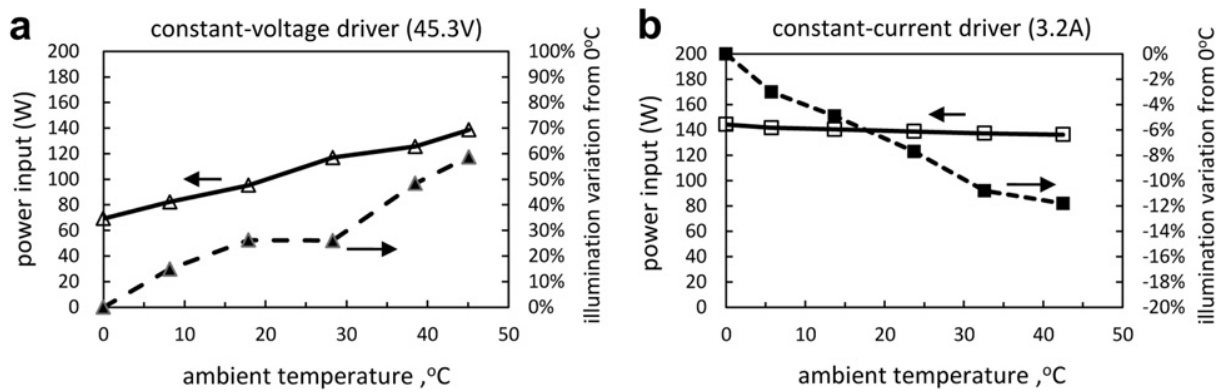

Fig. 2. Variation of LED illumination with temperature for different driver. 


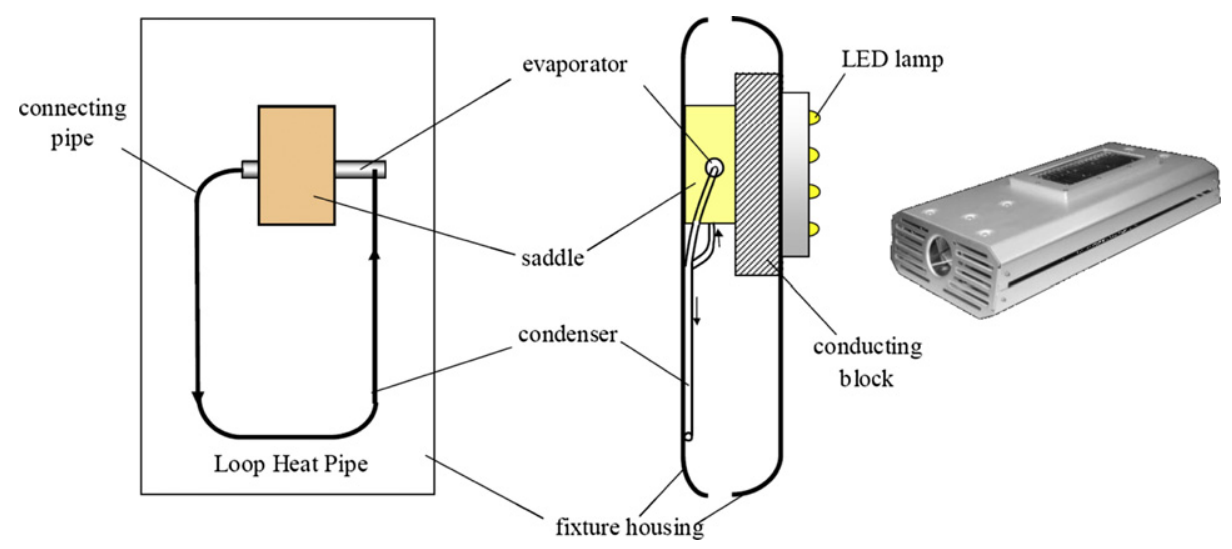

Fig. 3. Design of LED luminaire using loop heat pipe [2].

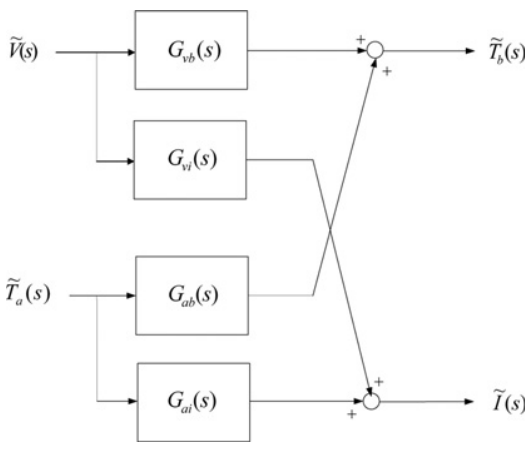

Fig. 4. MIMO block diagram of an LED luminaire [4].

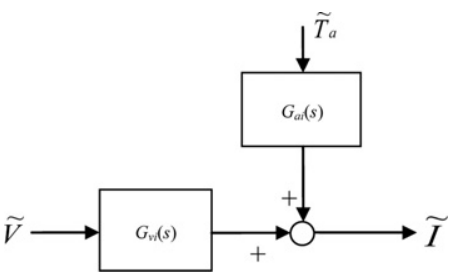

Fig. 5. Simplified linear model of LED luminaire [4].

$$
\begin{aligned}
P(t) & =I(t) \times V(t)=[\bar{I}+\tilde{I}(t)] \times[\bar{V}+\tilde{V}(t)] \\
& =\overline{I V}+\bar{I} \tilde{V}(t)+\tilde{I} \bar{V}+\tilde{I}(t) \tilde{V}(t)=\bar{P}+\tilde{P}(t)
\end{aligned}
$$

Since $\bar{P}=\overline{I V}$, Eq. (8) becomes

$$
\tilde{P}(t)=\bar{I} \tilde{V}(t)+\tilde{I}(t) \bar{V}+\tilde{I}(t) \tilde{V}(t)
$$

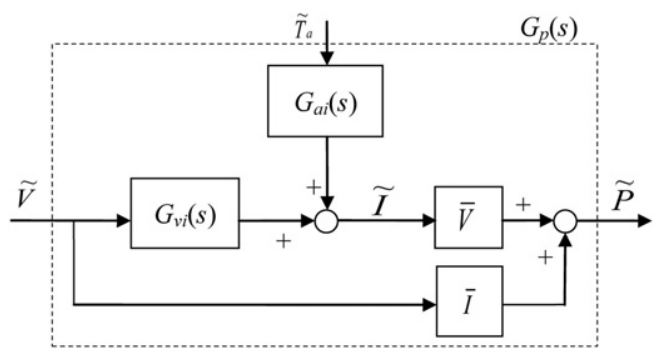

Fig. 6. System dynamics model of LED luminaire.
The last term of Eq. (9), $\tilde{I} \tilde{V}$, is a nonlinear term which is negligible compared to other terms [9]. Hence, the linear model for the input power of LED luminaire is

$\tilde{P}(t)=\bar{I} \tilde{V}(t)+\bar{V} \tilde{I}(t)$

By connecting the above power input model to the simplified model (Fig. 5), we obtain a system dynamics model of LED luminaire, $G_{\mathrm{p}}(s)$, as shown in Fig. 6 , with input $\tilde{V}$ and output $\tilde{P}$.

\subsection{Identification of system dynamics model of an LED luminaire}

The model components of the LED system dynamic model, $G_{\mathrm{vi}}(s)$ and $G_{\mathrm{ai}}(s)$, needs to be identified from experiments at equilibrium state, $\bar{V}$ and $\bar{I}$.

\section{(1) Identification of model $G_{\mathrm{vi}}(s)$}

The LED forward current is a response of the applied voltage, i.e. the model component $G_{\mathrm{vi}}(s)=\tilde{I}(s) / \tilde{V}(s)$ represents a resistance, i.e. the current response to the input voltage at equilibrium points $(\bar{V}$ and $\bar{I})$. Since the current response $I$ caused by the voltage input $V$ is much faster than $1 \mathrm{~ms}$ in LED and can be approximated as an instantaneous process as compared to the thermal response. Hence, the voltage to current model $G_{\mathrm{vi}}(s)$ can be treated as a quasisteady system with a constant gain.

Actually, the gain of $G_{\mathrm{vi}}(s)$ is the slope of the $I-V$ curve of LED luminaire, i.e. electrical resistance. $G_{\mathrm{vi}}(s)$ can then be derived from a steady-state measurement of current-to-voltage relation ( $I-V$ curve).

The LED luminaire adopted in the present study is a $150 \mathrm{~W}$ highpower LED lighting fixture used in Ref. [5]. The design specification is shown in Table 1.

The $I-V$ curve of LED luminaire can be derived from the $I-V$ curve of a single LED lamps using network analysis. The single
Table 1

Design specification of $150 \mathrm{~W}$ LED lighting fixture.

\begin{tabular}{ll}
\hline Lighting fixture model & SL-914 \\
Fixture dimension, mm & $630 \times 315 \times 120$ \\
Total weight, kg & 8.5 \\
Number of LED lamps & 126 (9 parallel $\times 14$ series) \\
LED lamp efficacy, lm W ${ }^{-1}$ & 72 \\
Rated DC input power, W & $150 @ 49 \mathrm{~V}$ \\
Net output luminous flux, lm & 8836 \\
Specific weight, kg/1000 lm & 0.96 \\
Thermal resistance from LED & 0.20 in stagnant air \\
$\quad$ base to ambient, $\mathrm{K} \mathrm{W}^{-1}$ & \\
\hline
\end{tabular}




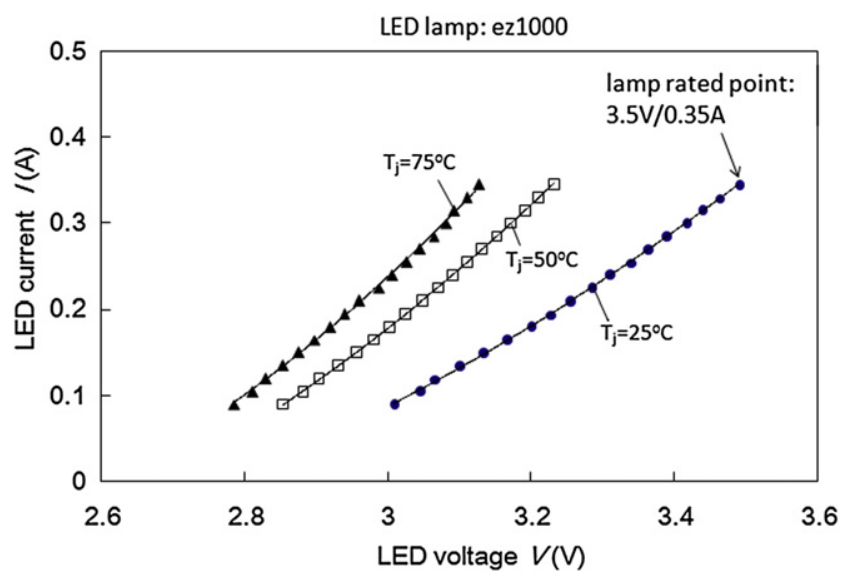

Fig. 7. $I-V$ curves of an LED lamp at different junction temperatures.

LED lamp is driven by a constant-voltage power supply and the current under different voltages are measured.

Since the $I-V$ curve varies with LED junction temperature, a cooling device made from a thermoelectric cooler with a control system was developed to control the LED junction temperature during the experiment. The measurement of LED junction temperature uses the pulse method developed by Huang et al. [10]. A low current pulse (1 mA) with short time duration $(50 \mu \mathrm{s})$ was applied to the LED lamp when the junction temperature is in equilibrium with the test chamber. The voltage was then measured and the junction temperature was determined using the predetermined $V-T_{j}$ relation at low current ( $1 \mathrm{~mA}$ ). The experiment was conducted for $T_{j}=25,50,75^{\circ} \mathrm{C}$. The measurement result of $I-V$ relation of LED lamp is shown in Fig. 7. A quadratic function can be derived to fit the $I-V$ curve of Fig. 7:

$I=a_{0} V^{2}-a_{1} V+a_{2}$

where $a_{0}, a_{1}, a_{2}$ are the fitted parameters for different junction temperature $T_{j}$.

Applying the perturbation relations, Eqs. (2) and (5), to Eq. (11) and neglecting the second-order term, $\tilde{V} \tilde{V}$, we obtain the following relation:

$\tilde{I}=\left(2 a_{0} \bar{V}-a_{1}\right) \tilde{V}$

Taking the Laplace transform of Eq. (12), we obtain the dynamics model for a single LED lamp:

$G_{\mathrm{vi}}(s)=\frac{\tilde{I}}{\tilde{V}}=2 a_{\mathrm{o}} \bar{V}-a_{1}$

The 150W LED luminaire used in the present study consists of 126 LED lamps with 14 in series and 9 in parallel. The dynamics model of the luminaire can be easily derived using electrical network

Table 2

Determination of the model parameters and $G_{v i}$ for a single LED lamp and the $150 \mathrm{~W}$ luminaire.

\begin{tabular}{llllll}
\hline$T_{j},{ }^{\circ} \mathrm{C}$ & $a_{\mathrm{o}}$ & $a_{1}$ & $a_{2}$ & $G_{\mathrm{vi}}$ (single LED) & $G_{\mathrm{vi}}$ (luminaire) \\
\hline 25 & 0.2037 & 0.7955 & 0.6408 & 0.5298 & 0.3406 \\
50 & 0.3140 & 1.2322 & 1.0487 & 0.6746 & 0.4337 \\
75 & 0.4193 & 1.7481 & 1.7069 & 0.7456 & 0.4793 \\
\hline
\end{tabular}
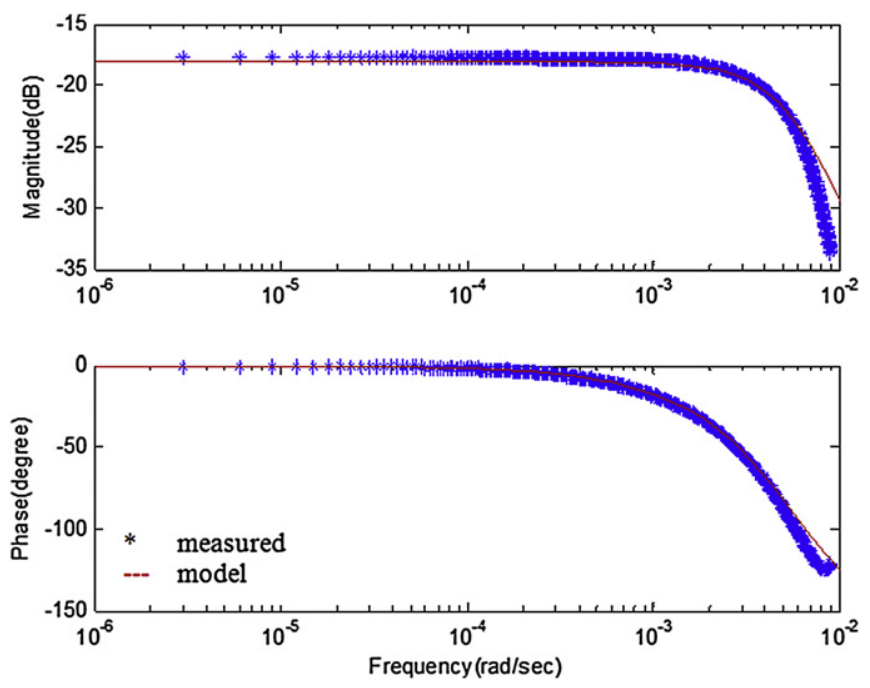

Fig. 8. Frequency response at $44 \mathrm{~V}$, step $T_{\mathrm{a}}: 28 \rightarrow 34{ }^{\circ} \mathrm{C}$.

principle. Table 2 shows the derived parameters $a_{0}, a_{1}, a_{2}$ and the model $G_{\mathrm{vi}}$ of a single LED lamp and the 150W LED luminaire.

\section{(2) Identification of model $G_{\mathrm{ai}}(s)$}

A step-response method which is the same as in Ref. [9] was used to identify the dynamics model $G_{\text {ai }}(s)$. By suddenly changing the ambient temperature $T_{\mathrm{a}}$ (by increasing the heating rate to the test chamber) from a steady-state operation (at fixed voltage $\bar{V}$ and current $\bar{I}$ ) and measuring the current response of the 150W LED luminaire, we can obtain the dynamics model from the data analysis. One of the results as shown in Fig. 8 indicates that the system dynamics model of $G_{\mathrm{ai}}(s)$ is a second-order since the phases approach $-180^{\circ}$ and the variation of the gain at high frequency is $-40 \mathrm{db} /$ decade. The following model can be used:

$G_{\mathrm{ai}}(s)=\frac{\tilde{I}(s)}{\tilde{T}_{\mathrm{a}}(s)}=\frac{k}{\left(s-p_{1}\right)\left(s-p_{2}\right)}$

The results of parameter identification of $G_{\mathrm{ai}}(s)$ are summarized in Table 3. An average model can be chosen for the control system design.

\section{Design of constant-power control system}

To obtain a constant power to LED luminaire requires a feedback control system for input power to the LED. Using the dynamics model derived in Section 2.1 (Fig. 6), a feedback control system for input power $P$ to the LED luminaire can be obtained as Fig. 9.

The PI (Proportional-Integral) algorithm was used for the controller $G_{c}(s)$ :

Table 3

Parameter identification of $G_{\text {ai }}(s)$ at different operating points.

\begin{tabular}{|c|c|c|c|c|}
\hline $\begin{array}{l}\text { Operating } \\
\text { point }\end{array}$ & $\begin{array}{l}\text { Voltage } \\
\text { (V) }\end{array}$ & $\begin{array}{l}\text { Step change } \\
\text { of } T_{\mathrm{a}}\left({ }^{\circ} \mathrm{C}\right)\end{array}$ & $p_{1}, p_{2}$ & $k$ \\
\hline 1 & 43 & $25^{\circ} \mathrm{C} \rightarrow 31^{\circ} \mathrm{C}$ & $-0.0009272 \pm 0.000565 i$ & $1.9040 \mathrm{e} 007$ \\
\hline 2 & 43 & $31^{\circ} \mathrm{C} \rightarrow 40^{\circ} \mathrm{C}$ & $-0.0008471 \pm 0.000527 i$ & $1.5503 \mathrm{e} 007$ \\
\hline 3 & 43.5 & $27^{\circ} \mathrm{C} \rightarrow 33^{\circ} \mathrm{C}$ & $-0.0013652 \pm 0.000758 i$ & $2.3655 \mathrm{e} 007$ \\
\hline 4 & 43.5 & $33^{\circ} \mathrm{C} \rightarrow 42^{\circ} \mathrm{C}$ & $-0.0011623 \pm 0.000569 i$ & $3.1662 \mathrm{e} 007$ \\
\hline 5 & 44 & $24^{\circ} \mathrm{C} \rightarrow 28^{\circ} \mathrm{C}$ & $-0.0011324 \pm 0.000566 i$ & $3.4331 \mathrm{e} 007$ \\
\hline 6 & 44 & $28^{\circ} \mathrm{C} \rightarrow 34^{\circ} \mathrm{C}$ & $-0.0019370 \pm 0.001143 i$ & $6.3379 \mathrm{e} 007$ \\
\hline Average & & & $-0.0012285 \pm 0.000688 i$ & $3.1255 \mathrm{e} 007$ \\
\hline
\end{tabular}




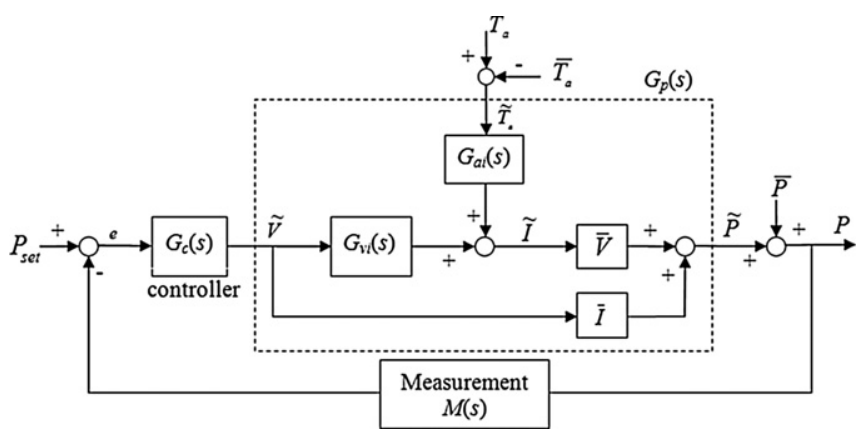

Fig. 9. Constant-power feedback control system of LED luminaire.

$G_{\mathrm{c}}(s)=K_{\mathrm{p}}+\frac{K_{\mathrm{i}}}{s}$

The design criteria for the constant-power feedback control system of LED luminaire is set as: rise time (the time of step response from $10 \%$ to $90 \%$ of the final stable value) $<2 s$; settling time (the time of step response to reach $98 \%$ stable value) $<5$ s. The transfer function of the feedback system is then derived as:

$H_{k}(s) \equiv \frac{\tilde{P}(s)}{P_{\mathrm{set}}(s)}=\left(1+G_{\mathrm{c}} G_{\mathrm{vi}} \bar{V}\right)^{-1}\left(G_{\mathrm{c}} G_{\mathrm{vi}} \bar{V}+G_{\mathrm{c}} \bar{I}\right)$

The controller $G_{c}(s)$ needs to be designed or tuned in such a way that the transfer function of the feedback system $H_{k}(s)$ approaches unity (no error) and satisfies the system design criteria, in the presence of disturbances. In addition, there is uncertainty in the system dynamics due to the change of operational condition, error in system identification, property variation of LED lamps in mass production, and decay of LED luminaire etc. If the controller $G_{c}(s)$ is properly designed, it can provide a robust property for correcting the effect of plant uncertainty. For the robust design purpose, the sensitivity function $S_{k}(s)$ is defined as the effect of plant uncertainty of $G_{\mathrm{vi}}(s)$ to the feedback system $H_{k}(s)$ :

$S_{k}(s)=\frac{\partial H_{k}}{\partial G_{\mathrm{vi}}} \frac{G_{\mathrm{vi}}}{H_{k}}=\left[\left(1+G_{\mathrm{c}} G_{\mathrm{vi}} \bar{V}+G_{\mathrm{c}} \bar{I}\right)\left(G_{\mathrm{vi}} \bar{V}+\bar{I}\right)\right]^{-1} G_{\mathrm{vi}} \bar{V}$

We also defined the sensitivity function $S_{\mathrm{V}}(s)$ as the effect of operating condition $\bar{V}$ to the feedback system $H_{k}(s)$ :

$S_{\mathrm{v}}(s)=\frac{\partial H_{k}}{\partial \bar{V}} \frac{\bar{V}}{H_{k}}=\left[\left(1+G_{\mathrm{c}} G_{\mathrm{vi}} \bar{V}+G_{\mathrm{c}} \bar{I}\right)\left(G_{\mathrm{vi}} \bar{V}+\bar{I}\right)\right]^{-1} G_{\mathrm{vi}} \bar{V}$

It is noted that $S_{k}(s)=S_{\mathrm{v}}(s)$.

We further defined the sensitivity function $S_{\mathrm{I}}(s)$ as the effect of operating condition $\bar{I}$ to the feedback system $H_{k}(s)$ :

$S_{\mathrm{I}}(s)=\frac{\partial H_{k}}{\partial \bar{I}} \frac{\bar{I}}{H_{k}}=\left[\left(1+G_{\mathrm{c}} G_{\mathrm{vi}} \bar{V}+G_{\mathrm{c}} \bar{I}\right)\left(G_{\mathrm{vi}} \bar{V}+\bar{I}\right)\right]^{-1} \bar{I}$

Table 4

Variation of rise time and settling time with controller designs $\left(K_{\mathrm{p}}, K_{\mathrm{i}}\right)$.

\begin{tabular}{lllllll}
\hline OP & 1 & 2 & 3 & 4 & 5 & 6 \\
\hline$K_{\mathrm{p}}$ & 0.05 & 0.08 & 0.1 & 0.15 & 0.2 & 0.25 \\
$K_{\mathrm{i}}$ & 0.05 & 0.06 & 0.06 & 0.08 & 0.09 & 0.09 \\
Rise time, s & 1.62 & 1.26 & 1.14 & 0.48 & 0 & 0 \\
Settling time, s & 3.84 & 3.96 & 4.38 & 3.9 & 4.32 & 3.84 \\
\hline
\end{tabular}

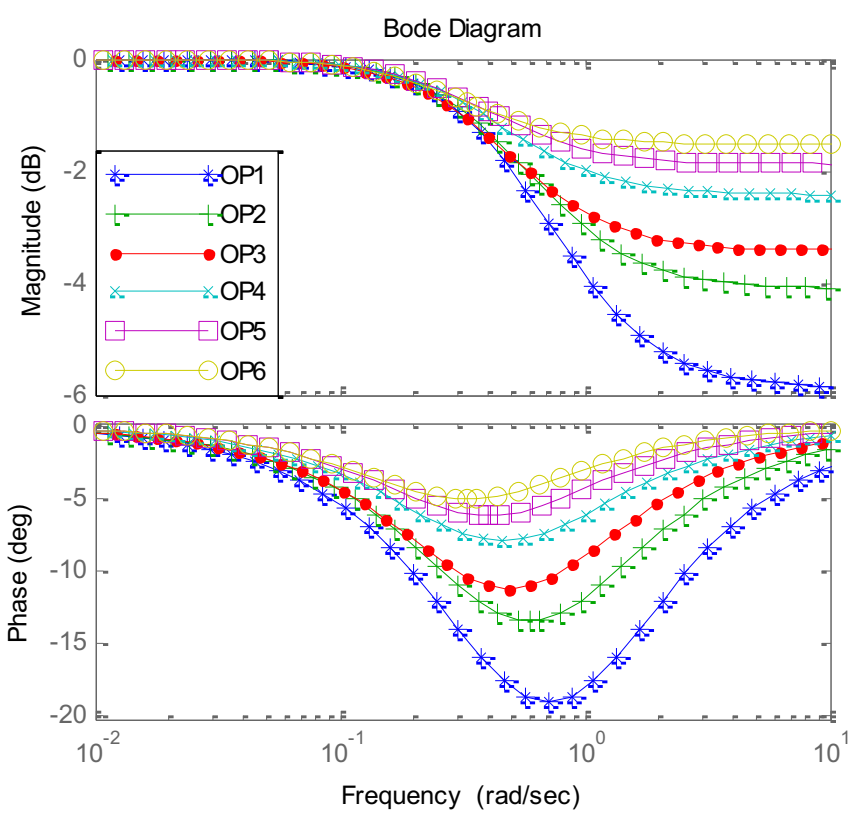

Fig. 10. Frequency response of $H_{k}(s)$ for different $K_{\mathrm{p}}$ and $K_{\mathrm{i}}$ listed in Table 4.

The controller design is actual a compromise between control accuracy, disturbance rejection, and plant uncertainty. The sensitivity functions $S_{k}, S_{\mathrm{v}}, S_{\mathrm{I}}$, are used to make a proper controller design associated with the feedback transfer function $H_{k}(s)$.

Since the average LED junction temperature in the luminaire is around $50{ }^{\circ} \mathrm{C}$ in practical application at night, we chose $G_{\mathrm{vi}}$ $(s)=0.4337$ from Table 2 . Therefore, the transfer function of the feedback system is:

$H_{k}(s)=\frac{20.7 K_{\mathrm{p}} s+20.7 K_{\mathrm{i}}}{\left(1+20.7 K_{\mathrm{p}}\right) s+20.7 K_{\mathrm{i}}} \quad$ at $T_{j}=50{ }^{\circ} \mathrm{C}$

The sensitivity functions then become:

$$
\begin{aligned}
& S_{k}(s)=S_{\mathrm{v}}(s)=\frac{0.9 s}{\left(1+20.7 K_{\mathrm{p}}\right) s+20.7 K_{\mathrm{i}}} \\
& S_{\mathrm{I}}(s)=\frac{0.098 s}{\left(1+20.7 K_{\mathrm{p}}\right) s+20.7 K_{\mathrm{i}}}
\end{aligned}
$$

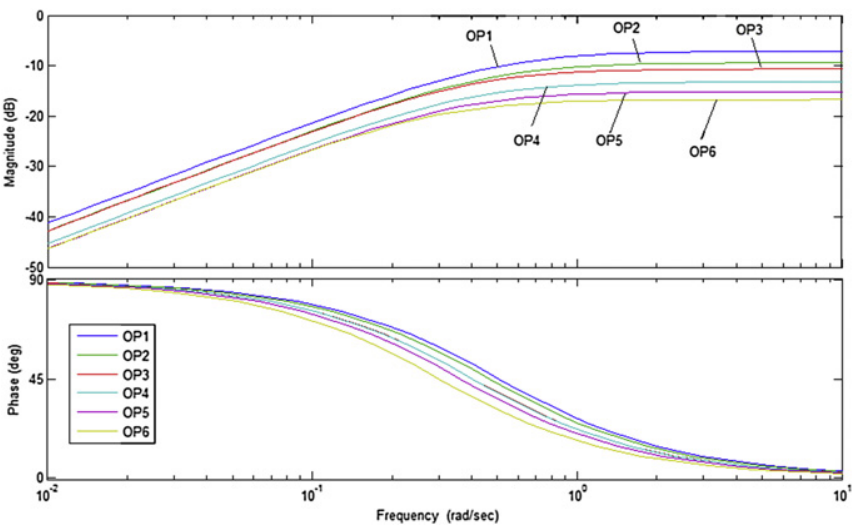

Fig. 11. Frequency response of $S_{k}\left(=S_{\mathrm{v}}\right)$ for different $K_{\mathrm{p}}$ and $K_{\mathrm{i}}$ listed in Table 4. 


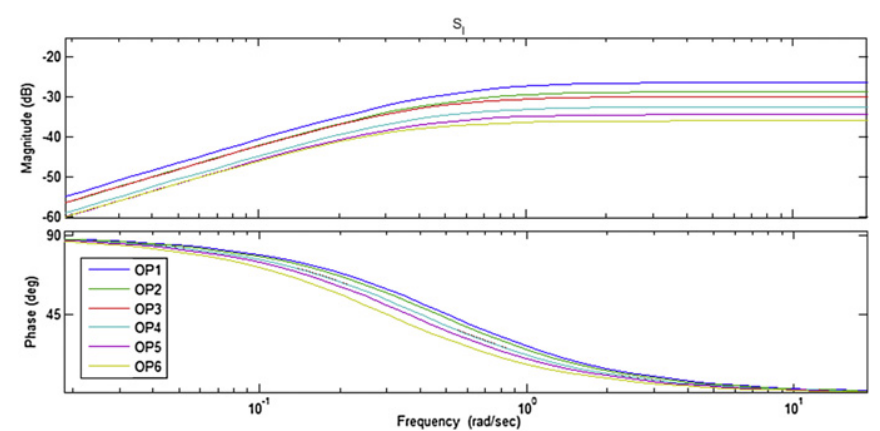

Fig. 12. Frequency response of $S_{\mathrm{I}}$ for different $K_{\mathrm{p}}$ and $K_{\mathrm{i}}$ listed in Table 4 .

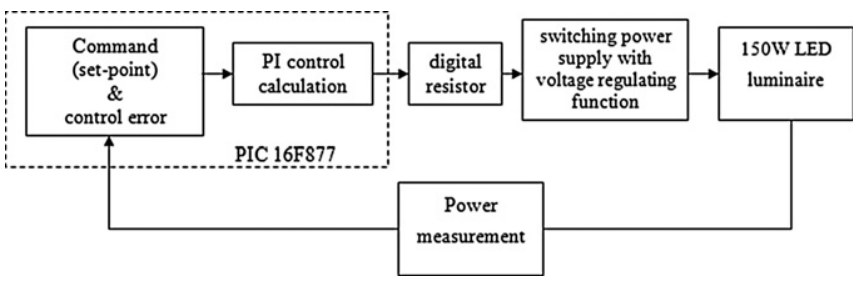

Fig. 13. Control system implementation.

The design of controller should first satisfy the feedback system stability which can be determined using Routh's stability criterion. Table 4 shows the variation of rise time and settling time with controller designs $\left(K_{\mathrm{p}}, K_{\mathrm{i}}\right)$. The bode plots of $H_{k}(s), S_{k}(s)$, and $S_{\mathrm{I}}(s)$ are shown in Figs. 10-12.

The frequency response of $H_{k}(s)$ shown in Fig. 10 indicates that, at frequency $1 \mathrm{rad} \mathrm{s}^{-1}$, the feedback control error is around $-4 \mathrm{db}$ (gain 0.53) for the design OP1 (highest control error) and $-1.5 \mathrm{db}$ (gain 0.84 ) for the design of OP6 (lowest control error).

The frequency response of sensitivity function $S_{k}\left(=S_{\mathrm{v}}\right)$ represents the sensitivity of the feedback control accuracy with respect to the uncertainty of plant dynamics $G_{\mathrm{vi}}(s)$ or the variation of operating condition $\left(S_{\mathrm{V}}\right)$. Fig. 11 shows that all the parameters of PI controller listed in Table 4 will result in a low sensitivity, $-40 \mathrm{db}$ (gain 0.01) in low frequency $\left(<10^{-2} \mathrm{rad} \mathrm{s}^{-1}\right)$ and $-10 \sim-20 \mathrm{db}$ (gain $0.32-0.10)$ in high frequency $\left(>1 \mathrm{rad}^{-1}\right.$ ). Much lower sensitivity is observed for $S_{\mathrm{I}}$, as shown in Fig. 12 .

The above analysis shows that the design OP6 $\left(K_{\mathrm{p}}=0.25\right.$ and $\left.K_{\mathrm{i}}=0.09\right)$ is the best in control error and sensitivity to plant uncertainty and variation of operating conditions and is adopted.

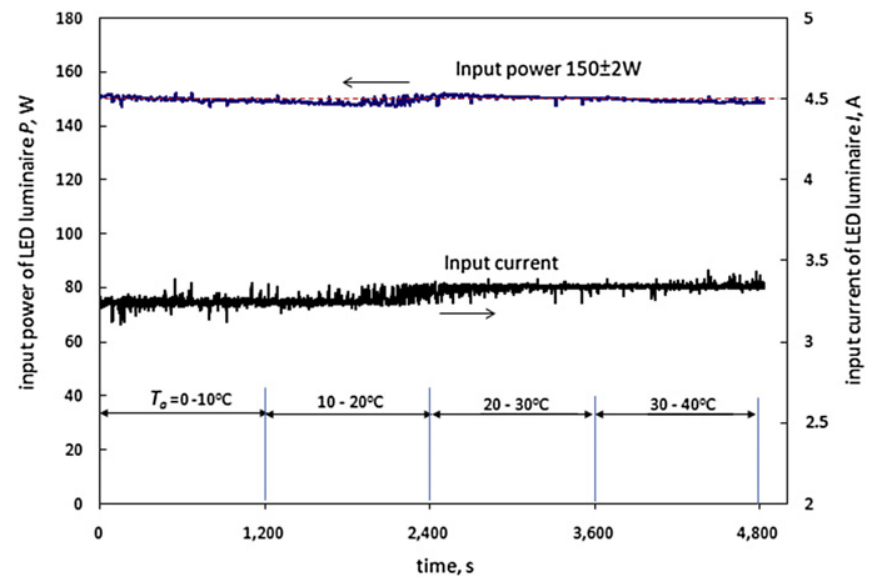

Fig. 14. Variation of input power and current with ambient temperature.
Table 5

Variation of input power and illumination of the $150 \mathrm{~W}$ LED luminaire with ambient temperature.

\begin{tabular}{lllllc}
\hline $\begin{array}{l}\text { Ambient } \\
\text { temperature } \\
\left({ }^{\circ} \mathrm{C}\right)\end{array}$ & $\begin{array}{l}\text { LED } \\
\text { voltage } \\
(\mathrm{V})\end{array}$ & $\begin{array}{l}\text { LED } \\
\text { current } \\
(\mathrm{A})\end{array}$ & $\begin{array}{l}\text { Input } \\
\text { power } \\
(\mathrm{W})\end{array}$ & $\begin{array}{l}\text { Illumination } \\
\text { (Lux) }\end{array}$ & $\begin{array}{l}\text { Change of } \\
\text { illumination } \\
(\%)\end{array}$ \\
\hline 10 & 45.7 & 3.28 & 149.8 & 986 & $0 \%$ \\
20 & 45.5 & 3.29 & 149.6 & 988 & $0.2 \%$ \\
30 & 45.2 & 3.32 & 150.0 & 975 & $-1.1 \%$ \\
40 & 45.0 & 3.34 & 150.3 & 969 & $-1.7 \%$ \\
\hline
\end{tabular}

The effect of ambient temperature change with respect to the feedback control accuracy can be ignored since the sensitivity function $S_{\mathrm{Ta}}(s)=1$ which is defined as

$S_{\mathrm{Ta}}(s)=\frac{\partial H_{\mathrm{t}}}{\partial G_{\mathrm{ai}}} \frac{G_{\mathrm{ai}}}{H_{\mathrm{t}}}=1$

where $H_{\mathrm{t}}(s)$ is the power input $\mathrm{P}$ response due to ambient temperature change Ta:

$H_{\mathrm{t}}(s) \equiv \frac{\tilde{P}(s)}{\tilde{T}_{\mathrm{a}}(s)}=\left(1+G_{\mathrm{c}} G_{\mathrm{vi}} \bar{V}+G_{\mathrm{c}} \bar{I}\right)^{-1} G_{\mathrm{ai}} \bar{V}$

\section{Control system test}

The result of the feedback control system design analysis described above was implemented on microprocessor PIC 16F877 as shown in Fig. 13. The control system utilizes the microprocessor PIC 16F877 as the central processing unit of the digital control system for command setting, control error detection, and controller calculation. The digital output is sent to a digital resistor (GS6267) which will regulate the voltage applied to the LED luminaire through the switching power supply. The current through LED luminaire is measured using a $0.005 \Omega$ resistor with an amplifier (IC MAX4373). Then, the power input of LED luminaire is determined by multiplying the current with the voltage.

The $150 \mathrm{~W}$ LED luminaire was put into an environmental chamber to run the test at different temperature $T_{\mathrm{a}}$, while the input power was set at $150 \mathrm{~W}$ and $T_{\mathrm{a}}$ was increased by $10^{\circ} \mathrm{C}$ every $20 \mathrm{~min}$ from $0{ }^{\circ} \mathrm{C}$ to $40{ }^{\circ} \mathrm{C}$. The test result of Fig. 14 has shown that the feedback system accurately controls the input power of LED

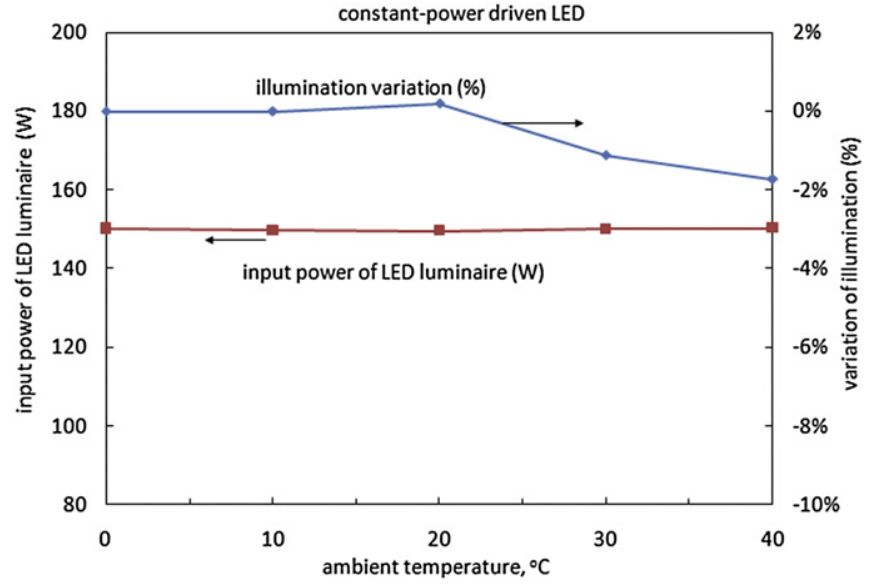

Fig. 15. Variation of LED illumination with ambient temperature at constant-power input. 
luminaire at $150 \pm 2 \mathrm{~W}$, within 1.3 per cent error. The input current gradually increases with increasing $T_{\mathrm{a}}$.

The illumination of the LED luminaire was also measured at a fixed location at steady state to see how the illumination varies with ambient temperature. Table 5 shows the input power and LED illumination at different ambient temperature. Fig. 15 shows the variation of LED illumination with ambient temperature at constant-power input. It is seen that, at the ambient temperature change from 0 to $40^{\circ} \mathrm{C}$, the LED illumination varies slightly $(-1.7 \%)$ for constant-power driving, as compared to that of constantcurrent driving $(-12 \%)$ and constant-voltage driving $(+50 \%)$ as shown in Fig. 2.

\section{Discussion and conclusion}

The test result has shown that the illumination of an LED is affected by operating temperature even under constant-current condition. A constant-power driving technique is then proposed for LED luminaire in the present study. Since the LED is a diode performing like a negative-temperature resistor which is a nonlinear component in control system design. A linear system dynamics model of LED luminaire is first derived and used in the design of the feedback control system. PI controller was adopted and tuned in the consideration of control accuracy and robust properties with respect to plant uncertainty and variation of operating condition. The control system was then implemented on a microprocessor and used to control a $150 \mathrm{~W}$ LED luminaire.

The test result has shown that the feedback system accurately controls the input power of LED luminaire to within 1.3 per cent error. It has shown that, at the ambient temperature change from 0 to $40^{\circ} \mathrm{C}$, the LED illumination varies slightly $(-1.7 \%)$ for constantpower driving, as compared to that of constant-current driving $(-12 \%)$ and constant-voltage driving $(+50 \%)$. The constant-power driving has revealed advantage in stabilizing the illumination of LED under large temperature variation. This is quite important in practical application since a constant illumination is always necessary. In the application of color lighting using LED, the steady illumination from R-G-B lamps is much more important for accurate color control under the variation of environmental conditions.

\section{Acknowledgements}

This publication is based in part on work supported by Energy Bureau, Ministry of Economic Affairs, Taiwan, and Award No. KUKC1-014-12, made by King Abdullah University of Science and Technology (KAUST), Saudi Arabia.

\section{Nomenclature}

$G_{\mathrm{ab}}(s) \quad$ transfer function from ambient temperature $T_{\mathrm{a}}$ to body temperature $T_{\mathrm{b}}$

$G_{\text {ai }}(s)$ transfer function from ambient temperature $T_{\mathrm{a}}$ to LED current $I$

$G_{\mathrm{c}}(s) \quad$ transfer function of controller in feedback system
$G_{\mathrm{vb}}(s)$ transfer function from LED voltage $V$ to LED body temperature $T_{\mathrm{b}}$

$G_{\mathrm{vi}}(s) \quad$ transfer function from LED voltage $V$ to current $I$

$H_{k}(s) \quad$ transfer function of the feedback control system, from setting point $P_{\text {set }}$ to input power $P$, Eq. (16)

$H_{\mathrm{t}}(s) \quad$ transfer function from ambient temperature $T_{\mathrm{a}}$ to input power $P$, Eq. (24)

I current to LED, A

$k \quad$ gain of LED model $G_{\text {ai }}(s)$, Eq. (14)

$K_{\mathrm{i}} \quad$ integral constant of PI controller

$K_{\mathrm{p}} \quad$ proportional constant of PI controller

$p_{1}, p_{2} \quad$ poles of LED model $G_{\text {ai }}(s)$, Eq. (14)

$P$ input power, $\mathrm{W}$

$P_{\text {set }} \quad$ setting of input power, $\mathrm{W}$

$s \quad$ Laplace variable, complex

$S_{k}(s) \quad$ sensitivity function for plant uncertainty $G_{\mathrm{vi}}$, Eq. (17)

$S_{v}(s) \quad$ sensitivity function for variation of operating voltage, Eq. (18)

$S_{\mathrm{I}}(s) \quad$ sensitivity function for variation of operating current, Eq. (19)

$S_{\mathrm{Ta}}(s) \quad$ sensitivity function for ambient temperature variation, Eq. (23)

$T_{\mathrm{a}} \quad$ ambient temperature, ${ }^{\circ} \mathrm{C}$

$T_{\mathrm{b}} \quad$ LED body temperature, ${ }^{\circ} \mathrm{C}$

$T_{j} \quad$ LED junction temperature, ${ }^{\circ} \mathrm{C}$

$t \quad$ time, $s$

$V \quad$ voltage to LED, $\mathrm{V}$

Symbols

- bar, equilibrium point

$\sim \quad$ tilde, perturbation

\section{References}

[1] J.T. Tsao, Solid-stage lighting: lamps, chips and materials for tomorrow, IEEE Circuits Dev. Magn. 20 (3) (2004) 28-37.

[2] The Promise of Solid State Lighting for General Illumination, Optoelectronics Industry Development Association, 2002, Website: http://lighting.sandia.gov/ lightingdocs/OIDA_SSL_Roadmap_Summary_2002.pdf.

[3] John W. Curran, Shawn P. Keeney, Replacement of fluorescent lamps with high-brightness LEDs in a bridge lighting application, sixth international conference on solid state lighting, Vol. 6337, 2006, J. Light Vis. Environ. 30 (2006) 177.

[4] B.J. Huang, C.H. Wang, T.T. Lin, H.H. Huang, Y.Y. Yeh, Development of a lowcost LHP for commercial application, in: 13th International Heat Pipe Conference, Shanghai, China. Sept.21-25 (2004).

[5] Bin-Juine Huang, Huan-Hsiang Huang, Chun-Wei Chen, Min-Sheng Wu, Development of high-power LED lighting luminaries using loop heat pipe, J. Light Vis. Environ. 32 (2) (2008) 148-155.

[6] M.S. Wu, H.H. Huang, B.J. Huang, C.W. Tang, C.W. Cheng, Economic feasibility of solar-powered LED roadway lighting, Renew. Energy (2009) 1934-1938.

[7] N. Narendran, R. Nissanka, A roadmap to sustainable lighting, Lighting India 5 (6) (2010) 30-35.

[8] Zetex Semiconductors Plc, ZXLD1320 Buck mode DC-DC converter for LED driving with 1.5A output and current control. Issue 1-January 2008. Website: http://www.zetex.com, 2008.

[9] Bin-Juine Huang, Po-Chien Hsu, Min-Sheng Wu, Chun-Wen Tang, Study of system dynamics model and control of a high-power LED lighting luminaire, Energy 32 (2007) 2187-2198.

[10] Bin-Juine Huang, Chun-Wen Tang, Min-Sheng Wu, System dynamics model of high- power LED luminaire, Appl. Thermal Eng. 29 (2009) 609-616. 